\title{
Comparison of Dubowitz scoring versus Ballard scoring for assessment of fetal maturation of newly born infants setting
}

\author{
Sangeeta Singhal $^{1}$, Ritu Bawa ${ }^{2 *}$, Shivani Bansal ${ }^{1}$ \\ ${ }^{1}$ Department of Pediatrics, ${ }^{2}$ Department of Obstetrics and Gynecology, Muzaffarnagar Medical College,
} Muzaffarnagar, Uttar Pradesh, India

Received: 10 May 2017

Accepted: 03 June 2017

*Correspondence:

Dr. Ritu Bawa,

E-mail: Ritu1.bawa@gmail.com

Copyright: $\odot$ the author(s), publisher and licensee Medip Academy. This is an open-access article distributed under the terms of the Creative Commons Attribution Non-Commercial License, which permits unrestricted non-commercial use, distribution, and reproduction in any medium, provided the original work is properly cited.

\begin{abstract}
Background: Different scoring systems based on neurological and physical examination are used in the neonatal units for assessment of gestational age. Assessment of gestational age is very much helpful in labelling the newborn to be preterm, term or post - term and to assess the further outcome of the newborn infants. Present study was performed to test the accuracy and reliability of the Ballard scoring system as compared to Dubowitz scoring system on 250 newborn infants and their correlation with the gestational age as calculated from first day of mother's last menstrual period. In infants of 38 weeks onwards correlation of gestational age was done with the extension of plantar creases over sole.

Methods: Infants studied were selected from infants born in Muzaffarnagar Medical College and Hospital Muzaffarnagar and those infants admitted to the neonatal intensive care unit. First of all methods of eliciting different criteria were experienced by examining several newborn infants and then Dubowitz and Ballard scoring system were performed separately and gestational age assessed. crease was measured, using metallic scale from base of great toe after stretching the sole.

Results: Gestational ages estimated by Ballard scoring system and Dubowitz system strongly correlated with the gestational ages computed from the date of mother's last menstrual period. The coefficient of correlation calculated between Ballard and Dubowitz scoring system showed perfect positive correlation on the regression line. Association of gestational age with the length of sole crease was also very significant.

Conclusions: The clinical test of maturation described by Ballard et al and which is evaluated in the present study, takes a balanced look at physical and neurological maturation and included those items found to be most useful regardless of the presence or absence of diseased state.
\end{abstract}

Keywords: Ballard scoring system, Dubowitz scoring system gestational age, Preterm

\section{INTRODUCTION}

Knowledge of maturity is useful in the timing of delivery in complicated pregnancies, evaluation of intrauterine growth, optimal management of a newborn infant, prediction of the infant's clinical course and subsequent developmental evaluation. Several methods of gestational age assessment have been proposed. The methods of Farr, Finnstrom and Parkin are based on external criteria, while those of Robinson and AmielTison are based on neurological criteria. It's been many years since studies first started describing ways in which pediatricians could assess the gestational maturity of the newborn baby. ${ }^{1,2}$ These studies were stimulated by a 
growing awareness that gestation was as important as weight in determining the hazards faced by the baby during and immediately after birth. ${ }^{3}$ Assessment of gestational age is very much helpful in labelling the newborn to be preterm, term or post term and to assess the further outcome of the newborn infants. Many influences determine the size of an infant at birth. Among those that have been studied are maternal characteristics such as height, social class and smoking habits, multiple pregnancies, the capacity and blood supply of uterus, the size and condition of the placenta, and intrinsic abnormalities of the fetus itself. The gestational age is most accurately measured by calculation from the first day of mother's last menstrual period, provided her cycles are regular and her memory is correct. Often, however, these conditions don't hold, and some independent method of assessing gestational age is required. Although separately neurological and physical criteria can estimate the gestational age but combining them makes the method more accurate. The medical problems expected in a preterm baby are different from a small for date baby. The prognosis with regard to subsequent mental and physical development is also different. A good method for assessment of gestational age should be quick and easy to perform, could be used in all ethnic group and even sick babies.

The neurological criteria may be affected by birth trauma, asphyxia and intrauterine factors. It also overestimates the gestational age of non-white babies. ${ }^{4,5}$ Assessments of physical criteria have also been used for the estimation of gestational age. The set of physical criteria initially defined by Farr et al. is commonly used. These criteria include skin colour, nipple formation, ear formation and plantar skin creases. The scoring system based on physical criteria alone is easier to use and may be more reliable in stressed babies. .,7 $^{6}$

With this little background in mind the present study was performed with the aims and objectives to study the reliability of the Ballard scoring system as compared to that of Dubowitz scoring system, to study the correlation of gestational age with that of individual component of the Ballard scoring system and to study the reliability of length of skin creases to the total length of the sole in assessing gestation age in newborns between 38 to 44 weeks of life.

\section{METHODS}

This is a diagnostic test evaluation. Study population was 250 term preterm babies born or admitted in a Tertiary care hospital Muzaffarnagar Medical College and Hospital, Muzaffarnagar

\section{Inclusion criteria}

Only those infants were included in the study whose mothers were able to give accurate information of first day of their last menstrual period and the period of gestation closely correlated with the clinical observations.

\section{Exclusion criteria}

Babies whose mothers did not know with certainty, the date of their last menstrual period, or whose menstrual periods were altered by the use of contraceptive pills or other drugs or maternal diseases were also excluded from the study. Babies with birth asphyxia and congenital malformations and sick babies with respiratory distress syndrome, congenital heart disease or septicemia also excluded from the study. The Institutional ethics committee of the Muzaffarnagar Medical College and Hospital approved the study protocol. First of all methods of eliciting certain neurology characteristics and labeling score for the various physical criteria, were experienced by examining several newborn infants. After getting well experienced with the various methods the present study was conducted. These infants were examined in between 30 hours and 42 hours of postnatal life, as has been advised by the Ballard scoring system.

The newborn infants were weighed using beam type of weighing machine, after correcting its zero error and weight was taken upto three decimal points of kilograms. The gestational age of the infants included in study group ranged from 27 weeks to 44 weeks.

\section{Measuring the sole creases}

In newborn with gestational age between 38 to 44 weeks the length of the sole (in centimeters) was measured from the base of the big toe to the prominent part of the heel and the length of the sole in which the skin creases present, was also measured. The length of creases was assessed by noting those persisting after stretching the skin of the sole. The measurement was done by using the metallic scale with clear cut graduations upto millimeters. If the length of sole creases differed on the two sided mean was taken and noted.

\section{Time required to complete the examinations}

To estimate the time required to complete the two scoring systems, a fellow post graduate student was asked to examine five neonates simultaneously, and the time required was calculated using a stop watch.

The average time required to complete the full Dubowitz ranged from 5 minutes and 50 seconds to 8 minutes and 5 seconds, averaging 6 minutes and 54 seconds. The time required to complete the Ballard scoring system ranged from 2 minutes and 50 seconds to 3 minutes and 50 seconds and averaged 3 minutes and 25 seconds, even when intensive care patients were included. The simplified score therefore, proved to be significantly more rapid $(\mathrm{t}=5.33, \mathrm{df}=4, \mathrm{P}<0.01)$, as well as to be useful in a broader group of infants. 


\section{RESULTS}

Present study was performed on 250 newborn infants born in the Department of Obstetrics and Gynecology and those admitted in Neonatal Intensive Care of Muzaffarnagar Medical College and Hospital, Muzaffarnagar. These newborn infants were examined within 30-42 hours of postnatal life.

\section{Distribution of cases according to maturity}

Out of these 250 cases, 75 were of less than 37 weeks' gestation (i.e. preterm), 169 of gestation 38 to 42 weeks (i.e. term), and 6 were of gestational age 43 and plus (i.e. post-term) as show in Table 1.

Out of these 250 cases, 246 were single ton while only 4 were twins. Out of these 250 cases, 175 were born after normal vaginal delivery, 25 after assisted vaginal delivery and 50 after lower segment cesarean section.
Table 1: Distribution of cases according to maturity.

\begin{tabular}{|lll|}
\hline Gestational age & Frequency & Percentage \\
\hline $27-37$ weeks & 75 & 30.0 \\
\hline $38-42$ weeks & 169 & 67.6 \\
\hline 43 weeks+ & 6 & 2.4 \\
\hline Total & 250 & 100 \\
\hline
\end{tabular}

\section{Relationship between birth weight of baby and gestational age}

To look for any relationship between birth weight and gestational age of the baby, the distribution of 250 cases is shown in Table 2. According to table there is increasing trend of birth weight as the gestational age advances. Out of 136 babies of gestational age beyond 39 weeks, 15 were weighing less than $2.5 \mathrm{~kg}$ (11.02\%) which is quite significant. The coefficient of correlation calculated is $\mathrm{r}=0.8533$, which is significant $(\mathrm{P}<0.001)$.

Table 2: Distribution of cases according to the birth weight and gestational age of baby.

\begin{tabular}{|c|c|c|c|c|c|c|c|c|}
\hline \multirow{2}{*}{$\begin{array}{l}\text { Gestational } \\
\text { age (weeks) }\end{array}$} & \multicolumn{8}{|c|}{ Birth weight (in kgms) } \\
\hline & $<\mathbf{1 . 0}$ & $1.0-1.5$ & $1.5-2.0$ & 2.0-2.5 & 2.0-.0 & 3.0+ & Total & Mean weight (kgms) \\
\hline $27-28$ & 5 & 3 & & & & & 5 & 1.062 \\
\hline $29-30$ & 3 & 7 & 10 & & & & 20 & 1.455 \\
\hline $31-32$ & 2 & 8 & 10 & 2 & & & 22 & 1.540 \\
\hline $33-34$ & & 3 & 8 & 6 & & & 17 & 1.838 \\
\hline $35-36$ & & 2 & 2 & 4 & & & 8 & 1.875 \\
\hline $37-38$ & & & 2 & 16 & 8 & 13 & 39 & 2.660 \\
\hline $39-40$ & & & 3 & 8 & 35 & 36 & 82 & 2.884 \\
\hline $41-42$ & & & & 4 & 8 & 36 & 48 & 3.083 \\
\hline $43-44$ & & & & & & 6 & 6 & 3.250 \\
\hline Total & 10 & 23 & 35 & 40 & 51 & 91 & 250 & \\
\hline
\end{tabular}

Table 3: Distribution of cases according to Dubowitz scoring system and gestational age from ist day of mother's last menstrual period.

\begin{tabular}{|c|c|c|c|c|c|c|c|c|c|c|}
\hline \multirow{2}{*}{$\begin{array}{l}\text { GA from LMP } \\
\text { (Weeks) }\end{array}$} & \multicolumn{9}{|c|}{ Gestational age from Dubowitz scoring system } & \multirow[b]{2}{*}{ Total } \\
\hline & 27-28 & 29-30 & 31-32 & 33-34 & $35-36$ & $37-38$ & $39-40$ & 41-42 & 43-44 & \\
\hline $27-28$ & & 8 & & & & & & & & 8 \\
\hline $29-30$ & & 4 & 16 & & & & & & & 20 \\
\hline $31-32$ & & 3 & 13 & 6 & & & & & & 22 \\
\hline $33-34$ & & & 4 & 11 & 2 & & & & & 17 \\
\hline $35-36$ & & & & 3 & 5 & & & & & 8 \\
\hline $37-38$ & & & & & 4 & 26 & 9 & & & 39 \\
\hline $39-40$ & & & & & & 5 & 72 & 5 & & 82 \\
\hline $41-42$ & & & & & & & 12 & 36 & & 48 \\
\hline $43-44$ & & & & & & & & 6 & & 6 \\
\hline Total & 0 & 15 & 33 & 20 & 11 & 31 & 93 & 47 & 0 & 250 \\
\hline
\end{tabular}




\section{Correlation of Dubowitz scoring system and gestational age from $1^{\text {st }}$ day of last menstrual period}

The bimodal frequency distribution of cases in the grouped series of gestational age from Dubowitz scoring system and that from $1^{\text {st }}$ day of last menstrual period is shown as

- The mean gestational age calculated from Dubwitz scoring system $(\mathrm{D})=37.316$.

- The standard deviation of mean gestational age from Dubowitz scoring system (S.D. of D) $=3.816$.

- The mean gestational age calculated from Ist day of last menstrual period $(\mathrm{L})=37.244$.

- The standard deviation of mean gestational age from Ist day of last menstrual period $(\mathrm{SD}$ of $\mathrm{L})=4.237$.
- The coefficient of correlation calculated is, $r=9584$, which is highly significant $(\mathrm{P}<0.001)$.

- The regression coefficient calculated is $b \quad \mathrm{DL}=$ +0.8631 .

- The equation calculated for regression line is $y$ $\mathrm{D}=5.171+0.8636 \mathrm{x}$ dates.

\section{Correlation of Ballard scoring system and gestational age from $1^{\text {st }}$ day of last menstrual period:}

The bimodal frequency distribution of cases in the group series of cases in the group series of gestational age from Ballard scoring system and that from $1^{\text {st }}$ day of last menstrual period is shown in Table 4.

Table 4: Distribution of gestational age from Ballard scoring system and ist day of mother's last menstrual period,

\begin{tabular}{|c|c|c|c|c|c|c|c|c|c|c|}
\hline \multirow{2}{*}{$\begin{array}{l}\text { GA from LMP } \\
\text { (Weeks) }\end{array}$} & \multicolumn{10}{|c|}{ Gestational age Ballard scoring system (weeks) } \\
\hline & 27-28 & 29-30 & 31-32 & 33-34 & $35-36$ & 37-38 & $39-40$ & 41-42 & 43-44 & Total \\
\hline $27-28$ & & 8 & & & & & & & & 8 \\
\hline $29-30$ & & 4 & 16 & & & & & & & 20 \\
\hline $31-32$ & & 2 & 14 & 6 & & & & & & 22 \\
\hline $33-34$ & & & 3 & 12 & 2 & & & & & 17 \\
\hline $35-36$ & & & & 3 & 5 & & & & & 8 \\
\hline $37-38$ & & & & & 4 & 23 & 12 & & & 39 \\
\hline $39-40$ & & & & & & 5 & 74 & 3 & & 82 \\
\hline $41-42$ & & & & & & & 3 & 44 & 1 & 48 \\
\hline $43-44$ & & & & & & & & & 6 & 6 \\
\hline Total8 & 0 & 14 & 33 & 21 & 11 & 28 & 89 & 47 & 7 & 250 \\
\hline
\end{tabular}

Coefficient of correlation $(r)=0.9717, \mathrm{P}<0.001$

Table 5: Distribution of cases according to Ballard scoring system.

\begin{tabular}{|c|c|c|c|c|c|}
\hline \multirow{2}{*}{$\begin{array}{l}\text { GA } \\
\text { according to } \\
\text { LMP(Weeks) }\end{array}$} & \multicolumn{5}{|c|}{$\begin{array}{l}\text { Gestational age according Ballard } \\
\text { (weeks) }\end{array}$} \\
\hline & $27-28$ & $\begin{array}{l}29- \\
30\end{array}$ & $\begin{array}{l}31- \\
32\end{array}$ & 33-34 & Total \\
\hline $27-28$ & 0 & 8 & & & 8 \\
\hline $29-30$ & & 4 & 16 & & 20 \\
\hline $31-32$ & & 2 & 14 & 6 & 22 \\
\hline $33-34$ & & & 3 & 14 & 17 \\
\hline Total & 0 & 14 & 33 & 20 & 67 \\
\hline Coefficient of & orrelati & $(\mathrm{r})$ & .7738 & $P<0.00$ & \\
\hline
\end{tabular}

- The mean gestational age calculated from Ballard scoring system $(B)=37.460$.

- The standard deviation of mean gestational age from Ballard scoring system (S.D. of L) =4. 237.

- The mean gestational age calculated from last menstrual period $(\mathrm{L})=37.244$.

- The standard deviation of mean gestational age from last menstrual period (S.D. of L) $=4.237$.
- The coefficient of correlation calculated is, $r=0.9717$, which is highly significant $(\mathrm{P}<0.001)$.

- The regression coefficient calculated is, b $\mathrm{BL}=0.8853$.

- The equation for regression line calculated is $\mathrm{YB}=$ $4.488+0.885 \mathrm{X}$ dates.

Of those infants, whose gestational age was 30 weeks or less 10 out of 28 had an anterior vascular capsule judged to be grade 4 . No infant of more than 30 weeks had a grade of 4 (Table 7).

Relationship of length of sole creases to the gestational age in infants in between 38 and 44 weeks

120 cases estimated to be in between 38 and 44 weeks of gestational (inclusive) were included in the present study. The range of percentage of length of sole creases to the total length of sole ranged from $66.66 \%$ to $97.24 \%$. Two infants of gestational age less than 39 weeks had percentage of sole creases less than $70 \%$, while none beyond 39 weeks of gestational had sole creases less than $70 \%$ (Table 6). No infant of 42 weeks of gestational of 
gestational or more had percentage of length of sole creases less than $80 \%$.

Table 6: Distribution of cases in bimodal grouped series for percentage of sole creases.

\begin{tabular}{|l|lllll|l|l|}
$\begin{array}{l}\text { GA } \\
\text { (Weeks) }\end{array}$ & $\begin{array}{l}\text { Percentage of length of } \\
\text { sole creases }\end{array}$ & & \multicolumn{2}{l|}{$\begin{array}{l}\text { Total } \\
\text { mean }\end{array}$} \\
& $<\mathbf{7 0}$ & $\mathbf{7 0 - 8 0}$ & $\mathbf{8 0 - 9 0}$ & $\mathbf{9 0 - 1 0 0}$ & & \% \\
\hline $38-39$ & 2 & 9 & 22 & 4 & 37 & 82.59 \\
\hline $40-41$ & & 5 & 30 & 30 & 65 & 83.59 \\
\hline $42-43$ & & & 3 & 10 & 13 & 91.65 \\
\hline $44+$ & & & 1 & 4 & 5 & 91.89 \\
\hline Total & 2 & 14 & 56 & 48 & 120 & \\
\hline$X^{2}$ value $=$ & 31.093 & & & & \\
\hline
\end{tabular}

From Table 6, it is predicted that mean percentage of length of sole creases has an increasing trend as the gestational age advances. The chi square $\left(x^{2}\right)$ value calculated is $=31.093$. At 12 degree of freedom, at $5 \%$ significant level the expected $\mathrm{x} 2$ value is 27.79 . Since the observed value is higher so it is significant.

Therefore, the positive association of length of gestational age and percentage of sole creases is proved.

\section{Correlation of ballard scoring system and doubowitz scoring system}

The bimodal frequency distribution of cases in the group series of gestational age Ballard scoring system and that from Dubowitz scoring system is show in Table 7.

Table 7: Distribution of gestational age from Ballard scoring system and dubowitz scoring system.

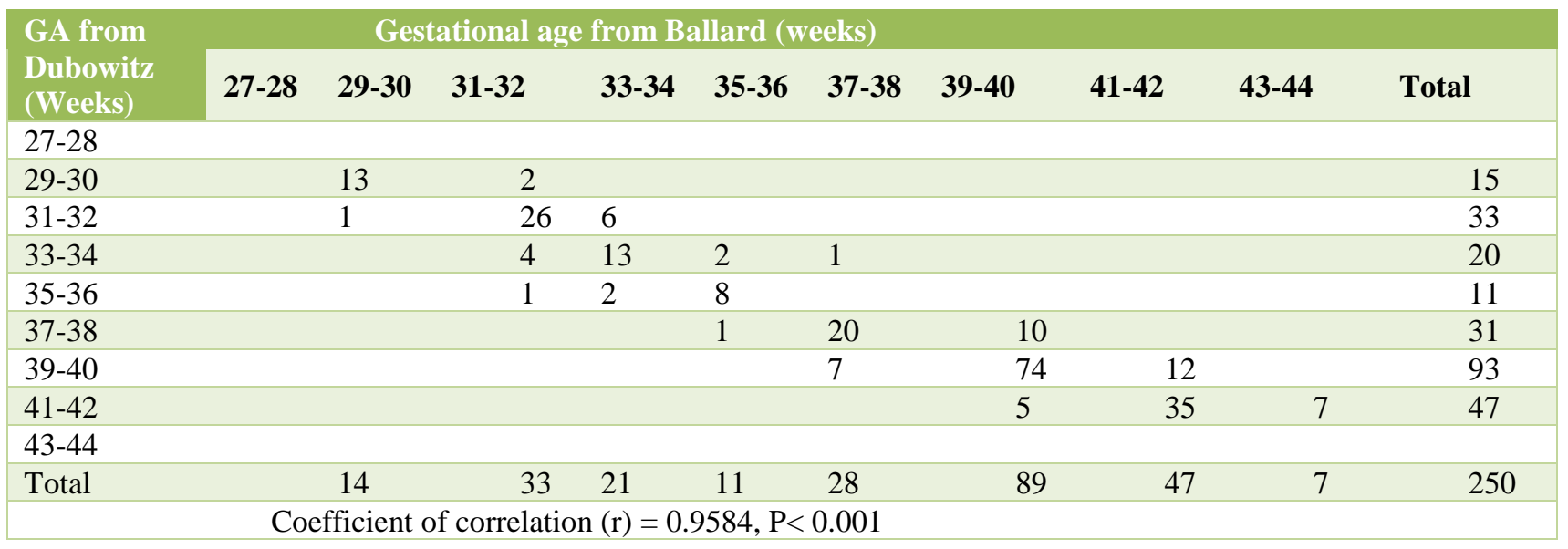

- The mean gestational age calculated from Ballard scoring system $(\mathrm{B})=37.460$.

- The standard deviation calculated from the mean gestational age from Ballard (S.D. of B) $=3.860$.

- The mean gestational age calculated from Dubowitz scoring system $(D)=37.316$.

- The standard deviation of the mean gestational age from Dubowitz scoring system (S.D. of D) $=3.816$.

- The coefficient of correlation, $r=0.958$ ( $\mathrm{P}<0.001)$.

- The regression coefficient calculated is $\mathrm{bBD}=0.969$.

- The equation for regression line is - $\mathrm{YB}=1.272+$ 0.969 x Dubowitz.

Therefore, it is proved that Ballard scoring system is equally effective in assessing gestational age as Dubowitz scoring system, although, it has an added advantage of having less number of criteria.

Both Dubowitz and Ballard scoring systems have perfect positive correlation with the gestational age as calculated from last menstrual period.

\section{DISCUSSION}

The word maturity which commonly refers to the fully developed adult state, is used in neonatal Pediatrics with two different meanings. Maturation is a continuing process related to changing physiological needs, and no single point on the spectrum can be considered as representing maturity. It must not be expected that any one observation, or even group of observations, however precisely made and evaluated, will give an absolute measure of the stage of maturation. The real importance of assessing the stage of maturation of the newborn infants lies in determining his ability to respond to the challenge of post-natal life and relating that response to the outcome in terms of survival and integrity. In the present study, an attempt has been made to make a protocol for the assessment of gestational age as accurately as possible considering various influential factors. GA assessment was performed at mean time of 14 hours 7 minutes, thus avoiding factors that decrease the accuracy of physical criteria. ${ }^{8}$ In the present series the 
correlation between weight and gestational age was although close $(\mathrm{r}=0.8533, \mathrm{P}<0.001)$, but if prematurity is considered to be less than 37 weeks' gestation than $11.02 \%$ of these babies were premature by weight but not by dates (the so called small for date infants). Farr and Mitchell in their series presented loose correlation between weight and gestational age $(r=0.43)$ and $43 \%$ of these cases were not premature by dates. This is a serious short coming, therefore birth weight is not popular as an index of maturity assessment. ${ }^{9}$

Parity has been found to have a positive association with gestational age $\left(x^{2}=80.25, \quad \mathrm{P}<0.001\right.$. $)$ Moreover, the incidence of prematurity is also much higher in early parities $\left(\mathrm{P}_{1}=40 \%, \mathrm{P}_{2}=33.34 \%\right)$. The same thing has been proved by several authors also. Of many methods that have been explored, the clinical ones appear to give the best prediction of gestational age and clearly only these are likely to be of widespread value in newborn nurseries. In this attempt, Dubowitz et al were very successful. They presented an excellent manual of estimating gestational age and the $95 \%$ confidence limit was achieved upto 2 weeks by combining 10 neurological criteria with 11 external physical characteristics described by Farr et al (improving the $95 \%$ confidence limits of 2.4 weeks as calculated by Farr et al using external characteristics alone). But the use of such a large number of measures diminish the value of the method, as the necessary skills for examination are more difficult to acquire, the examination becomes time consuming and is more disturbing for an ill baby.

Parkin et al used only 4 characteristics; skin color, skin texture, breast size and ear firmness. They obtained a $95 \%$ confidence levels of 18 days. But the most important drawbacks with this scoring system are: there is an intrinsic subjectiveness in describing and scoring skin color and texture, which represent one half of the scoring system and their data included fewer small for gestational age babies. ${ }^{10,11}$ Erman et al compared New Ballard Score and Finnstorm score against ultrasonographic assessment of gestational age. ${ }^{10}$ They found that the strength of correlation between either NBS or Finnstromscore and USG assessment of gestational age are similar. Sreekumar K et al. compared New Ballard sore with the Parkin score and found the two methods to be in acceptable agreement. ${ }^{12,13}$ The correlation between gestational age determined from dates and from Ballard examination, as has been calculated in the present study, is comparable. The difference is not statistically significant.

The coefficient of calculated for Ballard scoring system is, $\mathrm{r}=0.9717(\mathrm{P}<0.001)$ and is near to the coefficient of correlation $(\mathrm{r}=0.852)$ as calculated by Ballard et al. The correlation determined for Dubowitz scoring is, $r=0.9584$ ( $<<0.001)$ again comparable to that calculated by Ballard et al $(\mathrm{r}=0.848)$. The correlation between the total scores obtained from the Ballard and Dubowitz scoring system is, $\mathrm{r}=0.9584 \quad(\mathrm{P}<0.001)$, again comparable to that calculated by Ballard et al $(r=0.969, \mathrm{P}<0.001)$. Thus, the reliability of the simplified Ballard scoring system is comparable to that of the Dubowitz examination.

The clinical test of maturation described by Ballard et al and which is thus evaluated in the present study, takes a balanced look at physical and neurological maturation and includes those items found to be most useful regardless of the presence or absence of disease. Some authors prefer, in the interest of time, to eliminate the neurologic aspects of maturation, but this is undesirable, since neurologic criteria aid in the assessment of infants of less than 34 weeks' gestation. Neurologic changes which occur between 26 and 34 weeks are appreciable, whereas physical changes consist of a replacement of extensor tone by flexor tone progressing in a caudocephalad direction. Furthermore, inclusion of neurologic criteria enables the examination to assess functional or physiologic maturation in addition to physical development. In the present study, also it has been proved that by reducing the criteria, the accuracy of estimating gestational age is not affected $(r=0.9717$, $\mathrm{P}<0.001) .{ }^{14}$ The gestational age is more closely related to the individual components of the physical assessment than to the neurologic criteria of both the Dubowitz and Ballard scoring systems. The correlation for the score obtained for the total Ballard assessment is greater than that obtained by any of its individual components. Thus, the total Ballard score is more accurate, both the individual components of the test and the total score are a reliable assessment of maturation and of the length of gestation.

The clinical test of maturation described by Ballard et al and which is thus evaluated in the present study, takes a balanced look at physical and neurological maturation and includes those items found to be most useful regardless of the presence or absence of diseased. The disappearance of the anterior vascular capsule of the lens was found to be of value in estimating gestation age. There was a significant negative correlation (Table 5) between gestational age and grade of anterior vascular capsule $(\mathrm{r}=-0.9635, \mathrm{P}<0.001)$ and it is comparable to that calculated by Hittner et al $(\mathrm{r}=-0.877, \mathrm{P}<0.001)$. of those infants, whose gestational age was 30 weeks or less, 35 . $6 \%$ had an anterior vascular capsule judged to be grade 4 . As compared to this Hittner et al judged about $50 \%$ of infants less than 30 weeks of gestation to be grade of 4 $\left(\mathrm{x}^{2}=16.37, \mathrm{P}<0.001\right)$, finding which is similar to that found by Hittner et al. Of those infants, whose gestational age was 31 weeks or greater, $41.03 \%$ had an anterior vascular capsule judged to be grade 1 and no infant of gestational age less than 31 weeks had a grade of $1\left(\mathrm{x}^{2}=\right.$ 16.05, $\mathrm{P}<0.001)$.

In comparison to this Hittner et al found $51.8 \%$ of infants, of gestational age more than 31 weeks, having anterior vascular capsule judged to be grad 1 and only infant of gestational age less than 31 weeks had a grade of 1. Thus Grades 4,3,2 and 1 were found to correlate 
with gestational ages 27 and 28 weeks, 29 and 30 weeks, 31 and 32 weeks, and 33 weeks and 34 weeks, respectively. This grading system is an arbitrary division of a continuous process and, therefore, in using this grading system, if a decision of grade can not be made, it is suggested that the grades be adjusted accordingly: Grade 4/3 +, 28-29 weeks; grade 3/2+, 30-31 weeks; grade $2 / 1+32-33$ weeks. In post term infants' assessment of gestational age by the creases can be quite accurately judged. The technique of measuring the length of sole creases is quite simple. But care must be taken to measure the length of sole crease after stretching the skin of sole.

Thus, in the present study the accuracy of Ballard scoring system is once again proved. But since the system is somewhat weak in very premature infants, grading of anterior vascular capsule may be used as a criterion in estimating the gestational age in infants of less than 34 weeks of gestation. In term and post term infants Ballard scoring system is quite accurate and length of sole creases may be used additionally to increase the sensitivity of assessing the gestational age.

\section{CONCLUSION}

- In newborn infants, gestational age should be assessed by Ballard scoring system.

- In very premature infants, assessment of gestational age is best done by grading anterior vascular capsule of lens.

- In term and post-term infants utilising Ballard scoring system additional help may be taken by measuring the length of sole creases.

Funding: No funding sources

Conflict of interest: None declared

Ethical approval: The study was approved by the Institutional Ethics Committee

\section{REFERENCES}

1. Farr V, Mitchell RG, Neligan GA, Parkin JM. The definition of some external characteristics used in the assessment of gestational age. Dev Med Child Neurol. 1966;8:507-11.

2. Farr V, Kerridge DF, Mitchell RG. The value of some external characteristics in the assessment of gestational age at birth. Dev Med Child Neurol. 1966;8:657-60.
3. Dunn PM. The respiratory distress syndrome of the newborn. Immaturity versus prematurity. Arch Dis Child. 1965;40:62-5.

4. Simon CS, Cullinan J, Stinsons, McAnarney ER. Effect of race on validity of clinical estimates of gestational age. J Pediatr. 1989;115:1000-1.

5. Alexander GR, de Caunes F, Hulsey TC, Tompkins ME, Allen M. Ethnic variation in postnatal assessments of gestational age: a reappraisal. Paediatr Perinat Epidemiol. 1992;6(4):423-33.

6. Farr V, Kerridge DF, Mitchell RG. The value of some external characteristics in the assessment of gestational age at birth. Dev Med Child Neurol. 1966;8:657.

7. Farr V, Mitchell RG, Neiligan GA, Parkin JM. The definition of some external characteristics used in assessment of gestational age in the newborn infant. Develop Med Child Neurol.1996;8: 507.

8. Erman, Wayan R, Soetiningsih. Clinal gestational age assessment in newborns using the new Ballard score. Paediatr Indones. 2006;46:97-102.

9. Farr V, Mitchell RG, Neligan GA, Parkin JM. The definition of some external characteristics used in the assessment of gestational age in the newborn infant. Dev Med Child Neurol. 1966;8(5):507-11.

10. Parkin JM. The assessment of gestational age in Ugandan and British newborn babies. Dev Med Child Neurol. 1971 Dec;13(6):784-8.

11. Parkin JM, Hey EN, Clowes JS. Rapid assessment of gestational age at birth. Arch Dis Child. 1976;51(4):259-63.

12. Erman, Wayan R, Soetjiningsih. Clinical gestational age assessment in newborns using the new Ballard score. Pediatr Indones. 2006;46:97-102.

13. Sreekumar K, D'lima A, Nesargi S, Rao S, Bhat S. Comparison of New Ballards Score and Parkins score for gestational age estimation. Indian Pediatr. 2013;50:771-7.

14. Ballard JL, Khoury JC, Wedig KL, Wang L, EilersWalsman BL, Lipp R. New Ballared Score, expanded to include extremely premature infants. J Pediatr. 1991;119(3):417-23.

Cite this article as: Singhal S, Bawa R, Bansal S. Comparison of Dubowitz scoring versus Ballard scoring for assessment of fetal maturation of newly born infants setting. Int J Reprod Contracept Obstet Gynecol 2017;6:3096-3102. 